Hematol Oncol Clin North Am. 2009 June ; 23(3): 383-vii. doi:10.1016/j.hoc.2009.03.010.

\title{
Melanoma Epidemiology
}

\author{
Margaret A. Tucker, MD \\ aDirector, Human Genetics Program and Chief, Genetic Epidemiology Branch, Division of Cancer \\ Epidemiology and Genetics, National Cancer Institute
}

\section{Keywords}

melanoma; risk factors; nevi; UV; genetics

\begin{abstract}
With the rapid increases in the incidence of melanoma in the United States, Australia, and Europe over the last decades, melanoma has been considered an epidemic cancer in these areas. Many epidemiologic studies have been conducted to evaluate the etiology of melanoma. These studies have included descriptive population registry-based studies, which yield important information about trends in specific areas but usually do not have individual level information; analytic studies, often case-control, which may include not only individual exposure information but also host factors and phenotype; and family studies, which may be phenotype-intensive, designed in large part to identify susceptibility genes. Most recently, with the advent of genome-wide association studies, agnostic assessment of genetic variation across the genome as risk factors for melanoma has been possible. A comprehensive review of all of these results is not feasible within the limits of this manuscript; only recent advances based on epidemiologic studies will be included.
\end{abstract}

\section{U.S. Population Melanoma Rates}

Melanoma incidence has continuously increased in the Surveillance, Epidemiology, and End Results (SEER) program over the last 30 years (Table 1) ${ }^{1}$. In 2005, the age-adjusted incidence was 24.6 per 100,000 for men and 15.6 per 100,000 for women. There is a well described lag in reporting of melanomas ${ }^{2}$, so the estimates in Table 1 reflect delay-adjusted incidence. In the 1970's the rate of increase was higher, but the estimated annual percent change (EAPC) is currently $2.9 \%$ per year overall in the United States. This overall rate of increase, however, disguises the extensive variability in incidence. Melanoma, similar to other adult onset cancers, is a complex, heterogeneous cancer. Incidence rates differ between genders, ages, ethnic groups, and regions. Before age 40, incidence is higher in each age category in young women; over age 40 , incidence increases rapidly in men, but the rate of increase slows dramatically in women ${ }^{3}$. This unusual incidence pattern has led to hypotheses about hormonal influences in melanoma etiology which have been investigated in numerous studies ${ }^{4: 5}$. More recently, using newer analytic methods, the population patterns have been explored as manifestations of the heterogeneity in melanoma ${ }^{3 ; 6}$. Lachiewicz et al. assessed patterns of melanoma by age, gender, and anatomic site. Within anatomic site (trunk and face/ears), they also compared superficial spreading and nodular melanomas. They found different age-specific patterns consistent with divergent causal pathways ${ }^{6}$. Anderson et al. recently evaluated age of onset of melanoma by gender, histopathologic classification and anatomic site. Gender, histopathology and anatomic site were age-specific effect modifiers for melanoma. The crossing of the incidence curves of males and females at age 40 is

Corresponding author for proof and reprints: Margaret A. Tucker, MD Genetic Epidemiology Branch 6120 Executive Blvd Rm 7122 Bethesda, MD 20892-7236 (301) 496-4375 (301) 402-4489 (fax) tuckerp@ mail.nih.gov. 
consistent with bimodal age distributions. Age-period-cohort models were used to simultaneously assess age, calendar period and cohort effects by gender. A combination of female, lower extremity site and superficial spreading melanoma was mostly early-onset in age, but the combination of male, head and neck or upper extremity site and lentigo maligna melanomas was mostly late-onset in age ${ }^{3}$. These groups are two that could be clearly differentiated among likely many subgroups that can be variously categorized. Another aspect of heterogeneity in melanoma is reflected in the differing histologic subtypes and anatomic distributions of melanoma across ethnicities in the U.S. ${ }^{1 ; 7}$. Little is known about the etiology of melanoma in these groups, but among Hispanics in California, the rates appear to be increasing in all tumor thicknesses ${ }^{8}$.

Purdue et al. recently evaluated the incidence and mortality patterns of melanoma in teenagers and young adults under age 40 from 1973-2004 . The incidence rate in young men increased substantially between 1973 and 1980 (EAPC 6.6\%; $\mathrm{p}=0.0010$, but has been relatively flat since (EAPC $0.4 \% ; \mathrm{p}=0.35$ ). There is some hint that the rates may be beginning to increase again in the last few years. In young women, however, from 19731978, the increase was quite steep (EAPC 9.2\%; $<$ 0.0001). From 1978-1987 the rate of increase was less (EAPC 2.6\%; $\mathrm{p}=0.0001$ ). The incidence then stabilized for several years. Since 1992, the incidence has increased steadily at the earlier pace (EAPC 2.7\%; $<<0.0001$ ). The incidence rates rose for both thicker and thin melanomas, and for both localized and regional/distant disease. These patterns are suggestive of a gender-specific change in exposure patterns.

Melanoma mortality rates have not increased as dramatically as the incidence rates ${ }^{1}$. The mortality rates are based on the entire U.S. population, not just the areas covered by the SEER registries. From 1975-1989, overall mortality increased (EAPC 1.6\% p <0.05)), but has been stable since (EAPC -0.1). For men, the mortality rates increased from 1975-1990 (EAPC 2.2\%; $\mathrm{p}<0.05$ ), but flattened 1990-2005 (EAPC 0.1). The modeled age-adjusted mortality rate for men in 2005 is 3.9 per 100,000. For women, the mortality rate increased more slowly than for men from 1975-1988 (EAPC 0.8\%; $<<0.05$ ), but then decreased from 1988-2005 (EAPC -0.6\%; p 0.05). The 2005 mortality rate for women is 1.7 per 100,000 and has essentially returned to the 1976 mortality rate.

The discrepancy in the rate of increase in the incidence and the mortality has led to the hypothesis of "non-metastasizing melanoma" 10 . The argument is that there is overdiagnosis or misdiagnosis of early lesions that are not biologically significant, leading to an inflation of the incidence ${ }^{11 ; 12}$. Against this, however, is the concurrent increase in thicker, more advanced lesions ${ }^{9}$, especially in those of lower socioeconomic status ${ }^{13}$. Another interpretation of the discrepancy between the incidence and the mortality is that with greater awareness of melanoma, thinner lesions are being found earlier at a curative stage, resulting in lower mortality. This issue is likely not going to be resolved until there are better prognostic markers for excised lesions and better identification of lesions to excise.

\section{Analytic Studies of Melanoma Etiology}

Most of the individual analytic studies have not been large enough to have sufficient power to evaluate subgroups of melanoma, however defined. There is also great heterogeneity in study designs, definition of risk factors, collection of data, and extent of phenotyping (e.g., self reports to physician exams). It is therefore difficult to pool data, conduct meta-analyses, or directly compare results across studies. Meta-analyses use aggregate data; pooled analyses need to "harmonize" the individual level data, usually not at the finest level of detail for exposures or phenotypes. Therefore, risks that are seen in these combined analyses are likely to be lower than in the more pristine studies. Despite these difficulties, clear risk 
factors have evolved over the past several decades. Increased number of nevi, no matter how evaluated, is an important risk factor. Other host factors with consistently demonstrated risks include complexion, tanning ability, extent of freckling, and family history of melanoma. Most studies also find that ultraviolet exposure is the most important environmental factor related to melanoma risk.

The majority of studies assessing number of nevi combine all nevus types; some separate nevi by size; few classify and enumerate total body dysplastic nevi and common nevi. In general, studies with only combined nevus counts report odds ratios on the order of 4-6 for the highest count category. When only common acquired nevi are included, the risks are on the order of $2-4^{14}$. In a recent meta-analysis of 47 studies including 10499 cases and 14256 controls, Gandini et al were able to extend distribution of risks across finer categories ${ }^{15}$. Among the 26 studies with whole body counts of common nevi, the relative risks [RR] rose from 1.47 (95\% confidence intervals [CI] 1.36-1.59) for 16-40 nevi to 6.89 (95\% CI 4.6310.25 ) for 101-120. There have also been two recent pooled analyses of nevi as a risk factor for melanoma ${ }^{16 ; 17}$. There is major overlap of the studies in the two analyses (two of ten in Olsen's study are not included in Chang's study), but somewhat different endpoints were assessed. Olsen was testing the hypotheses that increased number of nevi would be related to melanomas arising in areas of less sun exposure and higher nevus counts such as the back, and that nevi would be less strong risk factors for melanomas arising on constantly exposed skin, such as the head and neck. Analyses included women only (2406 cases and 3119 controls); the pooled dataset had been created to evaluate reproductive factors. As a surrogate for $M C 1 R$ variation, they also analyzed the combined effect of nevus number, hair color and freckling. The most frequent nevus variable assessed was count of nevi on the $\operatorname{arm}(\mathrm{s})$. Only two studies had observer counted nevi on most of the body. They found that the risk of melanoma related to the highest number of nevi was strongest for trunk (5-fold increased) melanomas and limb (legs 3-fold; arms 4-fold increased) melanomas. The association was less strong, and not statistically significant, for head and neck melanomas. These findings are consistent with their hypothesis. When freckling and red hair were combined with the nevus variable, the pooled odds ratio (pOR) rose from 4.5 (95\% confidence intervals [CI] 1.3-15.7) in the highest nevus category without freckling or red hair to 7.3 (95\% CI 2.7-19.7) with high nevus counts and freckling to 14.4 (95\% CI 2.0102 ) in the small group ( 24 cases; 8 controls) with high nevus counts and red hair, with or without freckling. Site specific melanoma risks could not be addressed in the analyses including the red hair variable in this large data set.

Chang's hypothesis was that melanoma risk associated with nevi might vary by latitude ${ }^{17}$. Latitude was considered in two levels: northern region (latitude $\geq 50 \mathrm{~N}$ ) and southern region (latitude $<50 \mathrm{~N}$ ). The pooled dataset included 15 case-control studies (5421 melanoma cases and 6966 controls), five of which had health care provider observed total body nevus counts. Three had atypical or dysplastic nevus counts. Because of the diverse data, nevus counts were considered in four strata for arm and total body counts separately in two age groups, $<50$ and $\geq 50$. The pORs for the highest categories ranged from 4.0 (95\% CI 2.5-6.4) for arm counts in those over age 50 to 6.9 (95\% CI 4.4-11.2) for whole body counts in those under age 50 . Variation in the studies using arm nevus counts was greater than in the studies reporting total body nevus counts. The pORs across latitudes were relatively similar. In the small number of studies with atypical nevi noted, any atypical nevi conferred a 4-fold increased risk of melanoma (95\% CI 2.8-5.8).

Relatively fewer studies have reported the risks of melanoma associated with dysplastic nevi and common nevi ${ }^{18}$. These studies with careful phenotyping are much more expensive to conduct because of the associated costs of professional exams. In addition, with the falling response rates in epidemiologic studies, accruing sufficient numbers of truly representative 
controls who are willing to dedicate the time and effort to participate has become increasingly difficult. Despite the relatively few studies, it is clear that clinically identified dysplastic nevi are important risk factors for melanoma. The usual clinical criteria include two obligate features: size greater than $5 \mathrm{~mm}$ in the largest diameter and a prominent flat component; and two of three additional features: irregular, asymmetric outline, indistinct borders, and variable pigmentation ${ }^{14}$. The histologic features include the presence of a disordered or immature growth pattern with a lymphocytic host response and random cytologic atypia in melanocytes ${ }^{19}$. Based on the findings from several case-control studies, these lesions are relatively common (about $10 \%$ [range 7\%-24\%] of adults) in populations of northern European descent ${ }^{18}$. The risks conferred by dysplastic nevi are much greater than those conferred by increased number of common nevi ${ }^{14}$. Among studies evaluating the role of dysplastic nevi in melanoma, dysplastic nevi are reported in $34 \%$ to $56 \%$ of melanoma cases ${ }^{18}$. Gandini et al. also evaluated the risks of melanoma associated with dysplastic nevi in their meta-analysis ${ }^{15}$. Among 13 studies with dichotomous data, any dysplastic nevi conferred a 10-fold increased risk of melanoma (95\% CI 5.04-20.32). Among 15 studies with continuous data on number of dysplastic nevi, the risk rose from 1.6 (95\% CI 1.38-1.85) for individuals with one dysplastic nevus to 10-fold increased (95\% CI 5.05-21.76) with 5 or more dysplastic nevi. There are likely population differences in the prevalence of dysplastic nevi; again, few studies have been conducted. A joint case-control study of melanoma in which nevi were assessed in the U.K. and Australia found that dysplastic nevi were three times more frequent in the Australian controls (6\%) than in the British controls (2\%), but the prevalence of nevi on non-sun exposed areas was the same ${ }^{20}$.

The etiology of nevi in general, and dysplastic nevi in particular, is not well characterized. There is evidence from twin studies of a genetic component to the etiology of nevus counts ${ }^{21-24}$. Candidate regions have been evaluated but no causal or susceptibility genes have been confirmed to date ${ }^{25}$. There are increasing data that sun exposure is important in the pattern of development and number of nevi ${ }^{26-28}$. Limited data exist for dysplastic nevi. Although common acquired nevi occur predominantly in intermittently sun exposed areas, dysplastic nevi also occur on areas with little or no sun exposure.

Virtually all studies of melanoma have demonstrated that light skin color (RR 2.06; 95\% CI 1.68-2.52), poor tanning ability (RR 2.09; 95\% CI 1.67-2.58), light eye (RR 1.47; 95\% CI 1.28-1.69) and hair (RR 1.78; 95\% CI 1.63-1.95) color are risk factors for melanoma and are highly correlated ${ }^{29}$. These complexion measures confer a relatively low risk, especially when the presence and number of nevi are adjusted for ${ }^{14}$. Red hair usually confers a higher risk (RR 3.64; 95\% CI 2.56-5.37) ${ }^{29}$, which likely reflects the presence of variation in $M C 1 R$. Freckling, a complex phenotype which represents not only susceptibility to sun and frequent $M C 1 R$ variation, but also extent of sun exposure, is measured in many ways across studies. Despite this hetereogeneity in assessment, freckling is almost always associated with risk of melanoma (RR $2.1 ; 95 \%$ CI $1.8-2.45)^{29}$.

The major environmental risk factor for melanoma is ultraviolet radiation (UVR). Sun exposure as a risk factor for melanoma has been extensively evaluated for decades; more recently, sunbed exposure has been assessed, also. In 1992, the International Agency for Research on Cancer concluded that there was sufficient evidence in humans for the carcinogenicity of sun exposure ${ }^{30}$. Several questions about the relationship of UVR to melanoma risk remain. It is difficult to collect lifetime history of a universal exposure. Earlier, English et al. assessed the reproducibility of recall of sun exposures at different ages among adults. They found that adult exposures appeared more reproducible than childhood exposures. Total sun exposure was also more reproducible than intermittent exposures ${ }^{31}$. Recently, Yu et al compared time-based (hours outdoors in the middle of the day) and activity-based (time outdoors according to specific activities) responses to self-administered 
questionnaires ${ }^{32}$. They found that the responses for childhood periods were similar for either method. For adult exposure, however, the activity-based approach was more reliable than the time-based approach (intraclass correlation coefficient [ICC] 0.69 versus $0.43, p=$ 0.003). There were distinct differences in the patterns for men and women; much of the improvement in the activity-based approach was in the women respondents. The men reported more time outdoors in both childhood and adult years. Few studies of sun exposure as a risk factor for melanoma have assessed the exposure patterns of men and women separately ${ }^{33}$. Fears at al. reported very different patterns of exposure between men and women; exposure patterns also varied by skin tanning ability, age, and geographic location $^{34}$. Even among individuals who tanned well, melanoma risk increased with increasing time outdoors.

Despite the difficulties in estimating exposure, meta-analysis of sun exposure in analytic studies has demonstrated increased risks ${ }^{33}$. For the purposes of this meta-analysis, "intermittent" exposure was largely recreational and elicited in most studies by asking about high exposure activities such as sunbathing, water sports, and sunny vacations. "Chronic" exposure was essentially occupational exposure. "Total" exposure was a combination of both chronic and intermittent. In the meta-analyses, genders were combined, and individual level data on exposure or phenotype were not available. Childhood (age $<15)$ and adult (>age 19) sunburns were also separated. Overall, total sun exposure was associated with a modest risk $(\mathrm{RR}=1.34 ; 95 \% \mathrm{CI} 1.02-1.77)$. There was heterogeneity in the studies included in this analysis that was explained partially by year of publication. Studies published before 1990 had lower risks $(\mathrm{RR}=0.92 ; 95 \% \mathrm{CI} 0.59-1.42)$ than those published later $(\mathrm{RR}=1.75 ; 95 \%$ CI 1.31-2.35). Intermittent sun exposure also conferred somewhat higher risk ( $R R=1.61$; 95\% CI 1.31-1.99), again with significant heterogeneity. This heterogeneity was attributed to variation in definitions of intermittent exposure, country of origin, and adjustment for phenotype or phototype. Chronic sun exposure, however, was not significantly associated with melanoma risk ( $R R=0.95 ; 95 \%$ CI $0.87-1.04)$, but again, there was evidence of heterogeneity. Two of the factors in the heterogeneity were controls with dermatologic conditions and latitude of the study ${ }^{33}$. At higher latitudes, there was a greater association between chronic exposure and melanoma $(\mathrm{p}=0.031)$. Sunburns conferred an increased risk in almost all of the studies included ( $R R=2.03 ; 95 \%$ CI 1.73-2.37). For history of sunburns, latitude affected risk estimates. Above 46 degrees (average latitude), the estimates were higher $(\mathrm{RR}=2.54 ; 95 \% \mathrm{CI} 1.99-3.24)$ than in lower latitudes $(\mathrm{RR}=1.91 ; 95 \% \mathrm{CI}$ 1.58-2.31). Timing of the sunburns, childhood or adult varied somewhat, but both appeared important and were not significantly different. In another meta-analysis of sunburns and melanoma risk, Dennis et al. found evidence for a dose-response relationship with number of sunburns and melanoma risk across childhood, adolescence, and adulthood ${ }^{35}$. Although childhood exposure is clearly important for melanoma risk, growing evidence suggests that sun exposure during all age periods affects melanoma risk.

Two recent meta-analyses have evaluated the risk of melanoma associated with sunbed use $^{36 ; 37}$. There is major overlap between the studies included in the two analyses. Not surprisingly, the findings were quite similar. Ever/never use of sunlamps/sunbeds was associated with melanoma in both ( $\mathrm{RR}=1.25$; 95\% CI 1.05-1.49; $\mathrm{RR}=1.15$; 95\% CI 1.00 1.31). Young age at first exposure conferred a somewhat higher risk $(\mathrm{RR}=1.69 ; 95 \% \mathrm{CI}$ 1.32-2.18; RR=1.75; 95\% CI 1.35-2.26). Gallagher et al. also evaluated longest duration or highest frequency of use and found similar risks ( $R R=1.61 ; 95 \%$ CI $1.21-2.12)$. Given the frequency of sunbed use in adolescents ${ }^{38}$ and the ready availability of indoor tanning facilities in the U.S. ${ }^{39}$, the increase of melanoma noted in young women by Purdue et al. may be a sentinel finding for a persistent future increase in young adults 9 . 
There are also biologic data and limited epidemiologic data that suggest a role of redoxactive metals in melanoma risk ${ }^{40}$. Most of the epidemiologic data derive from exposure cohorts, such as occupational cohorts or joint replacement cohorts. Neither group of cohorts has adequate sun exposure information to control for this major risk factor or to explore interactions with metal exposure. Despite the limitations, the role of metals in melanoma risk is intriguing and should be pursued.

Screening for melanoma remains controversial ${ }^{41}$. Fears et al. developed a melanoma risk assessment tool for primary care providers to identify individuals who might benefit from screening ${ }^{42}$. They first developed parsimonious relative risk models within a large casecontrol study that yielded attributable risks of $86 \%$ for men and $89 \%$ for women. Included were non-Hispanic whites who had no personal history of melanoma or non-melanoma skin cancers or family history of melanoma. Other ethnicities were excluded because the numbers were too sparse. Individuals with previous skin cancer or family history of melanoma should already be in skin screening programs as part of accepted best practices. Fears et al. then used SEER gender, age and location specific incidence rates to estimate a 5year absolute risk for an individual using age, gender, location, and limited phenotype markers accessible on the back (freckling, complexion, solar damage, number of nevi). These phenotypic makers are a measure of both susceptibility and exposure. The tool is available at http://www.cancer.gov/melanomarisktool/, but it needs to be validated in different groups. If validated, it could be useful as early screening tool to decide who is at sufficient risk to warrant full skin exam.

\section{Family and Genetic Susceptibility Studies}

Family history of melanoma confers approximately 2-fold increased risk of melanoma ${ }^{29 ; 43 ; 44}$. Family history of one relative is moderately frequent in the U.S.; one large study found $8 \%$ of cases had such a history ${ }^{44}$. Much more infrequent are families with three or more living members with melanoma; these are the families in which identification of high-risk susceptibility genes is possible. In the same study, only $0.4 \%$ of cases reported two or more relatives previously diagnosed with melanoma.

Familial melanoma is also heterogeneous. Two major susceptibility genes have been identified: $C D K N 2 A$ and $C D K 4$. CDKN2A codes for two different proteins, p16 (in the retinoblastoma pathway) and p14ARF (in the p53 apoptosis pathway). $C D K 4$ is also in the retinoblastoma pathway. CDKN2A mutations are identified in 39\% of 385 melanoma-prone families from Australia, North America, Europe, and Israel ${ }^{45}$. The prevalence of mutations varied by continent, with the lowest prevalence in Australia (20\%); intermediate in North America (45\%); and highest in Europe (57\%). Goldstein et al. examined several features previously associated with $C D K N 2 A$ mutations as predictors of mutation status across the different geographic areas. In Australia, the presence of multiple primary melanomas in two or more family members, median age of diagnosis less than or equal to age 40 , and six or more individuals in the family with melanoma was associated with mutations in CDKN2A. In North America, families with at least one individual with multiple primary melanomas and median age at diagnosis $\leq 40$ were more likely to have mutations. In Europe, $\geq 4$ individuals with melanoma in the family, one or more with multiple primary melanomas, age $\leq 50$ at diagnosis of melanoma, and history of pancreatic cancer in a family member predicted mutation status. These findings are consistent with the lower population rates of melanoma in Europe and higher rates of melanoma in North America and Australia. The lack of pancreatic cancer association in Australia could be due to the spectrum of mutations ${ }^{45}$. The penetrance of $C D K N 2 A$ mutations also varies across the continents. The overall cumulative risk of melanoma by age 80 among mutation carriers from families with $C D K N 2 A$ mutations is 0.67 (95\% CI 0.31-0.96), but ranged from 0.58 in Europe to 0.76 in 
the United States to 0.91 in Australia ${ }^{46}$. Population rates of melanoma were associated with the variation; this implies that factors important in determining melanoma in the general population are also important in high-risk families. The penetrance of melanoma by age 80 among individuals with $C D K N 2 A$ mutations unselected for family history of melanoma from Australia, the U.S. and Europe has been estimated to be 0.28 (95\% CI $0.18-0.40)^{47}$. The difference in penetrance among individuals in high risk families and those unselected for family history suggests that additional risk factors may be involved in the families with many affected individuals.

The frequency of mutations in $C D K 4$ is much lower than the frequency of $C D K N 2 A$ mutations. Among 466 families identified by GenoMEL, a consortium comprising melanoma genetics research groups from North America, Europe, Australia, and Asia, the prevalence of $C D K N 2 A$ and $C D K 4$ mutations was evaluated ${ }^{48}$. Mutations in $C D K N 2 A$ that affected only p14ARF (exon $1 \beta$ and large deletions), the alternative reading frame of $C D K N 2 A$, were considered separately from those that affect $\mathrm{p} 16$. Overall, $41 \%$ of families $(\mathrm{n}=190)$ had mutations; 178 of these affected p16. Of the remaining 12 mutations identified, 5 (1.8\%) affected CDK4 and 7 (2.5\%) affected p14ARF. Founder mutations in CDKN2A were the most frequent mutations in specific geographic locales (the Netherlands, Sweden, U.K.). The median age at diagnosis differs by mutation status within the families. In families with no mutation detected, the median age was 45 ; in those with $C D K N 2 A$ mutations 36 years; in those with p14ARF 30 years; and in those with $C D K 432$ years. The occurrence of tumors other than melanoma in family members was compared across the families with different mutations. As previously noted ${ }^{49}$, there was a strong relationship between pancreatic cancer and $C D K N 2 A$ mutations $(\mathrm{p}<0.001)$; the risk of pancreatic cancer also varied by specific mutations ${ }^{48}$. In contrast, no families with p14ARF mutations or $C D K 4$ mutations had pancreatic cancer. Families with p14ARF mutations (exon $1 \beta$ or large deletions) had a marginally significant association with neural tumors $(\mathrm{n}=2 / 7 ; \mathrm{p}=0.05)$; inclusion of families with $C D K N 2 A$ mutations that altered both p16 and p14ARF changed the association (9/99; $\mathrm{p}=0.12)$. No families with $C D K 4$ mutations had neural tumors. No significant association with uveal melanomas was found in any of the mutation groups.

Variations in $M C 1 R$ are important components of pigment diversity ${ }^{50}$. Multiple variants have been described and allele frequencies differ across populations; some variants are associated with red hair (RHC) and some are not (rhc). Variants differ in their associations with melanoma and non-melanoma skin cancer, but rhe variants as well as RHC variants confer increased risk. A recent meta-analysis of 22 studies that evaluated the association of nine common $M C 1 R$ variants (pV60L, pD84E, pV92M, pR142H, pR151C, pI155T, pR160W, pR163Q, and pD294H) and melanoma risk summarized risks of melanoma for each variant ${ }^{51}$. Risks ranged from 1.15 (95\% CI 0.92-1.43) for pV60L to 2.45 (95\% CI $1.32-4.55$ ) for pI155T. All but two, pV60L and pV92M, were significantly associated with melanoma risk. The five variants with significant association with red hair (pD84E, $\mathrm{pR} 124 \mathrm{H}, \mathrm{pR} 151 \mathrm{C}, \mathrm{pR} 160 \mathrm{~W}$, and $\mathrm{pD} 294 \mathrm{H})$ conferred melanoma risks from 1.43 (95\% CI $1.20-1.70)$ to 2.40 (1.50-3.84). Two others (pV92M, pI155T) were not associated with red hair; pV92M was also not significantly associated with melanoma risk (RR 1.22; 95\% CI $0.99-1.50)$. The other two variants (pV60L, pR163Q) were inversely associated with red hair; pR163Q was associated with melanoma risk (RR $1.42(1.09-1.85)^{51}$. Germline $M C 1 R$ variation has been associated with somatic $B R A F$ mutant melanomas, but not $B R A F$ wild type ${ }^{52 ; 53}$. These findings are consistent with the hypothesis that variants in $M C 1 R$ affect melanoma risk by other mechanisms than just pigmentation pathways.

Within melanoma-prone families, $M C 1 R$ variation increases risk of melanoma in families without $C D K N 2 A$ mutation $^{54}$ and modifies risk of melanoma associated with $C D K N 2 A$ mutations $^{55}$. Most cases in the $C D K N 2 A$ mutation-positive families had at least one $M C 1 R$ 
variant. Among $C D K N 2 A$ carriers, after adjustment for age, nevi, and pigmentation, multiple $M C 1 R$ variants conferred a 7-fold (95\% CI 1.6-33.2) increased risk of melanoma. Individuals with multiple primary melanomas were significantly more likely to carry multiple $M C 1 R$ variants. Age of onset was also younger for those with multiple $M C 1 R$ variants ${ }^{55}$. To explore the effects of $M C 1 R$ variants on risk of melanoma in carriers of one $C D K N 2 A$ founder mutation dating back approximately 97 generations, pG101W, Goldstein et al. evaluated melanoma-prone families from France, Italy, Spain, and the U.S. ${ }^{56}$ Overall, the risk of developing melanoma associated with multiple $M C 1 R$ variants was very similar $(\mathrm{RR}=7.2 ; 95 \% \mathrm{CI} 2.3-23.1)$. There was also a similar pattern of more frequent multiple $M C 1 R$ variants in multiple primary cases, but the association was weaker when the American families (included in the previous analysis) were removed. Most of the overall effect derived from the multiplex families. Two or more $M C 1 R$ variants were also associated with earlier age of onset in the individuals with multiple primary melanomas. The Italian families were significantly different from the other groups. There were fewer individuals with $M C 1 R$ variants, and no association between number of $M C 1 R$ variants and melanoma risk.

As noted above, although high risk susceptibility genes $C D K N 2 A$ and $C D K 4$ have been identified, they explain less than half of familial melanoma. It is unlikely that additional high risk susceptibility genes with a larger effect will be found, since multiple groups have been searching diligently since $C D K 4$ was identified in $1996^{57}$. To identify additional lower risk susceptibility genes by an agnostic approach, genome-wide association studies have been conducted by several groups. In a genome-wide scan of 864 melanoma cases and 864 controls from Australia, two SNPs of interest were identified, rs $17305657\left(\mathrm{p}=2.56 \times 10^{-7}\right)$ and $\mathrm{rs} 4911442\left(\mathrm{p}=2.39 \times 10^{-6}\right)^{58}$. These SNPs are approximately $1.5 \mathrm{Mb}$ apart on chromosome 20q. Replication of 33 SNPs selected for fine mapping across a $2.78 \mathrm{Mb}$ region on 20q was done in three sets of melanoma cases and controls totaling 2019 cases and 2105 controls. Two of the fine mapping SNPs (rs910873 and rs1885120) yielded higher significance than the original SNPs $\left(\mathrm{p}<1 \times 10^{-15}\right)$. The effects of these two SNPs could not be separated, and were not related to two candidate genes of interest are in the region, E2F1 and ASIP. The authors also explored per allele risk according to age at onset and found some evidence of a stronger effect in cases $\leq 40$ years old. The Icelandic group originally conducted a genome-wide scan of pigmentation characteristics in 2986 Icelandic individuals and identified six areas of interest ${ }^{59}$. They then replicated 9 SNPs in the six areas in 2718 additional Icelandic and 1214 Dutch individuals. They found a highly significant association of rs4785763 (OR $\left.=5.6 ; \mathrm{p}=3.2 \times 10^{-56}\right)$ located in $M C 1 R$ for red hair. They also identified a novel region on $6 \mathrm{p} 25.3$ best characterized by rs $1540771\left(\mathrm{OR}=1.4, \mathrm{p}=1.9 \times 10^{-9}\right)$ related to freckling and rs 1042602 in tyrosinase also related to freckling $\left(\mathrm{p}=1.5 \times 10^{-11}\right)$. Three SNPs in the first exons of SLC24A4 were significantly associated with hair color and eye color $\left(\mathrm{p}<1.9 \times 10^{-8}\right)$. SNPs in the known pigmentation gene OCA2 were significantly associated with eye and hair color; rs 1667394 showed the strongest risk $(\mathrm{OR}=35, \mathrm{p}=1.4 \times$ $10^{-124}$ for blue vs brown eyes). The final SNP was rs 12821256 on $12 \mathrm{q} 21.33$, which was significantly related to blond vs brown hair $\left(\mathrm{p}=3.8 \times 10^{-30}\right)$. The nearest gene to this SNP is KITLG. They then increased the sample size of the full scan to 5130 and replicated additional SNPs in 2116 Icelandic and 1214 Dutch individuals ${ }^{60}$. They found significant association $\left(\mathrm{p}=3.9 \times 10^{-9}\right)$ with burning and freckling with six SNPs in linkage disequilibrium on 20q11.22. A two-SNP haplotype, which they called the ASIP haplotype, accounts for the association and is highly significant in the combined analysis $\left(\mathrm{p}<10^{-24}\right)$. Two coding SNPs in TPCN2 were associated with blond vs brown hair $\left(\mathrm{p}<10^{-16}\right)$. One SNP in a linkage disequilibrium block that includes TYRP1 was significantly related to eye color $\left(\mathrm{p}=5.9 \times 10^{-17}\right)$. The eleven SNPs identified in these two studies and MC1R variants were then tested for association with melanoma in three groups from Iceland, Sweden, and Spain $^{61}$. A total of 1586 invasive and 407 in situ melanomas and 40094 controls were 
included. In the combined melanoma cases, there was a significant association with the ASIP haplotype (OR 1.45; 95\% CI 1.29-1.64; $\left.\mathrm{p}=1.2 \times 10^{-9}\right)$. The effect was stronger in the invasive than the in situ cases. There was also a significant association with the rs 1126809[A] variant of TYR (OR 1.21; 95\% CI 1.13-1.30; $\mathrm{p}=2.8 \times 10^{-7}$ ). Any MC1R variant conferred significant risk (OR 1.24; 95\% CI 1.17-1.32; $\mathrm{p}=1.6 \times 10^{-11}$ ). The effect was higher and more significant with RHC variants. Thus, to date, most of loci identified in genome-wide association studies seem related to pigmentation. Ongoing studies may yield additional informative loci.

With all of the epidemiologic studies in the past several decades (Table 2), we now can identify individuals at increased risk of melanoma and exposures related to melanoma. It is timely to consider translating this knowledge to appropriate interventions to decrease melanoma risk in the susceptible subgroups.

\section{Acknowledgments}

This work was supported by the Intramural Research Program, NCI, NIH

\section{Reference List}

1. Ries, LAG.; Melbert, D.; Krapcho, M.; Stinchcomb, DG.; Howlader, N.; Horner, MJ., et al. SEER Cancer Statistics Review, 1975-2005. National Cancer Institute; Bethesda, MD: 2008. Ref Type: Generic

2. Clegg LX, Feuer EJ, Midthune DN, Fay MP, Hankey BF. Impact of reporting delay and reporting error on cancer incidence rates and trends. J Natl Cancer Inst. 2002; 94(20):1537-1545. [PubMed: 12381706]

3. Anderson WF, Pfeiffer RM, Tucker MA, Rosenberg PS. Divergent cancer pathways for early-onset and late-onst cutaneous malignant melanoma. Cancer. 2009 in press. Ref Type: Generic

4. Karagas MR, Zens MS, Stukel TA, Swerdlow AJ, Rosso S, Osterlind A, et al. Pregnancy history and incidence of melanoma in women: a pooled analysis. Cancer Causes Control. 2006; 17(1):1119. [PubMed: 16411048]

5. Lea CS, Holly EA, Hartge P, Lee JS, Guerry D, Elder DE, et al. Reproductive risk factors for cutaneous melanoma in women: a case-control study. Am J Epidemiol. 2007; 165(5):505-513. [PubMed: 17158470]

6. Lachiewicz AM, Berwick M, Wiggins CL, Thomas NE. Epidemiologic support for melanoma heterogeneity using the surveillance, epidemiology, and end results program. J Invest Dermatol. 2008; 128(5):1340-1342. [PubMed: 18408748]

7. Bradford PT, Goldstein AM, McMaster ML, Tucker MA. Acral Lentigionus Melanoma: Incidence and Survival Patterns in the United States, 1986-2005. Arch Dermatol. 2009 in press.

8. Cockburn MG, Zadnick J, Deapen D. Developing epidemic of melanoma in the Hispanic population of California. Cancer. 2006; 106(5):1162-1168. [PubMed: 16429450]

9. Purdue MP, Freeman LE, Anderson WF, Tucker MA. Recent trends in incidence of cutaneous melanoma among US Caucasian young adults. J Invest Dermatol. 2008; 128(12):2905-2908. [PubMed: 18615112]

10. Burton RC, Armstrong BK. Non-metastasizing melanoma? J Surg Oncol. 1998; 67(2):73-76. [PubMed: 9486776]

11. Swerlick RA, Chen S. The melanoma epidemic: more apparent than real? Mayo Clin Proc. 1997; 72(6):559-564. [PubMed: 9179141]

12. Welch HG, Woloshin S, Schwartz LM. Skin biopsy rates and incidence of melanoma: population based ecological study. BMJ. 2005; 331(7515):481. [PubMed: 16081427]

13. Linos E, Swetter SM, Cockburn MG, Colditz GA, Clarke CA. Increasing Burden of Melanoma in the United States. J Invest Dermatol. 2009 
14. Tucker MA, Halpern A, Holly EA, Hartge P, Elder DE, Sagebiel RW, et al. Clinically recognized dysplastic nevi. A central risk factor for cutaneous melanoma. JAMA. 1997; 277(18):1439-1444. [PubMed: 9145715]

15. Gandini S, Sera F, Cattaruzza MS, Pasquini P, Abeni D, Boyle P, et al. Meta-analysis of risk factors for cutaneous melanoma: I. Common and atypical naevi. Eur J Cancer. 2005; 41(1):28-44. [PubMed: 15617989]

16. Olsen CM, Zens MS, Stukel TA, Sacerdote C, Chang YM, Armstrong BK, et al. Nevus density and melanoma risk in women: a pooled analysis to test the divergent pathway hypothesis. Int J Cancer. 2009; 124(4):937-944. [PubMed: 19035450]

17. Chang YM, Newton-Bishop JA, Bishop DT, Armstrong BK, Bataille V, Bergman W, et al. A pooled analysis of melanocytic nevus phenotype and the risk of cutaneous melanoma at different latitudes. Int J Cancer. 2009; 124(2):420-428. [PubMed: 18792098]

18. Tucker MA, Goldstein AM. Melanoma etiology: where are we? Oncogene. 2003; 22(20):30423052. [PubMed: 12789279]

19. Elder DE, Clark WH Jr. Elenitsas R, Guerry D, Halpern AC. The early and intermediate precursor lesions of tumor progression in the melanocytic system: common acquired nevi and atypical (dysplastic) nevi. Semin Diagn Pathol. 1993; 10(1):18-35. [PubMed: 8506414]

20. Bataille V, Grulich A, Sasieni P, Swerdlow A, Newton BJ, McCarthy W, et al. The association between naevi and melanoma in populations with different levels of sun exposure: a joint casecontrol study of melanoma in the UK and Australia. Br J Cancer. 1998; 77(3):505-510. [PubMed: 9472652]

21. Falchi M, Spector TD, Perks U, Kato BS, Bataille V. Genome-wide search for nevus density shows linkage to two melanoma loci on chromosome 9 and identifies a new QTL on 5q31 in an adult twin cohort. Hum Mol Genet. 2006; 15(20):2975-2979. [PubMed: 16928783]

22. Zhu G, Montgomery GW, James MR, Trent JM, Hayward NK, Martin NG, et al. A genome-wide scan for naevus count: linkage to CDKN2A and to other chromosome regions. Eur J Hum Genet. 2007; 15(1):94-102. [PubMed: 17063143]

23. Barrett JH, Gaut R, Wachsmuth R, Bishop JA, Bishop DT. Linkage and association analysis of nevus density and the region containing the melanoma gene CDKN2A in UK twins. Br J Cancer. 2003; 88(12):1920-1924. [PubMed: 12799637]

24. Zhu G, Duffy DL, Turner DR, Ewen KR, Montgomery GW, Martin NG. Linkage and association analysis of radiation damage repair genes XRCC3 and XRCC5 with nevus density in adolescent twins. Twin Res. 2003; 6(4):315-321. [PubMed: 14511439]

25. Celebi JT, Ward KM, Wanner M, Polsky D, Kopf AW. Evaluation of germline CDKN2A, ARF, CDK4, PTEN, and BRAF alterations in atypical mole syndrome. Clin Exp Dermatol. 2005; 30(1): 68-70. [PubMed: 15663508]

26. Gallagher RP, Rivers JK, Lee TK, Bajdik CD, McLean DI, Coldman AJ. Broad-spectrum sunscreen use and the development of new nevi in white children: A randomized controlled trial. JAMA. 2000; 283(22):2955-2960. [PubMed: 10865273]

27. Oliveria SA, Satagopan JM, Geller AC, Dusza SW, Weinstock MA, Berwick M, et al. Study of Nevi in Children (SONIC): baseline findings and predictors of nevus count. Am J Epidemiol. 2009; 169(1):41-53. [PubMed: 19001133]

28. Wachsmuth RC, Turner F, Barrett JH, Gaut R, Randerson-Moor JA, Bishop DT, et al. The effect of sun exposure in determining nevus density in UK adolescent twins. J Invest Dermatol. 2005; 124(1):56-62. [PubMed: 15654953]

29. Gandini S, Sera F, Cattaruzza MS, Pasquini P, Zanetti R, Masini C, et al. Meta-analysis of risk factors for cutaneous melanoma: III. Family history, actinic damage and phenotypic factors. Eur J Cancer. 2005; 41(14):2040-2059. [PubMed: 16125929]

30. IARC. IARC Monographs on the Evaluation of Carcinogenic Risks to Humans. Vol. vol. 55. Lyon, France: 1992. IARC Monographs on the Evaluation of Carcinogenic Risks to Humans: Solar and Ultraviolet Radiation.

31. English DR, Armstrong BK, Kricker A. Reproducibility of reported measurements of sun exposure in a case-control study. Cancer Epidemiol Biomarkers Prev. 1998; 7(10):857-863. [PubMed: 9796629] 
32. Yu CL, Li Y, Freedman DM, Fears TR, Kwok R, Chodick G, et al. Assessment of Lifetime Cumulative Sun Exposure Using a Self-Administered Questionnaire: Reliability of Two Approaches. Cancer Epidemiol Biomarkers Prev. 2009

33. Gandini S, Sera F, Cattaruzza MS, Pasquini P, Picconi O, Boyle P, et al. Meta-analysis of risk factors for cutaneous melanoma: II. Sun exposure. Eur J Cancer. 2005; 41(1):45-60. [PubMed: 15617990]

34. Fears TR, Bird CC, Guerry D, Sagebiel RW, Gail MH, Elder DE, et al. Average midrange ultraviolet radiation flux and time outdoors predict melanoma risk. Cancer Res. 2002; 62(14): 3992-3996. [PubMed: 12124332]

35. Dennis LK, Vanbeek MJ, Beane Freeman LE, Smith BJ, Dawson DV, Coughlin JA. Sunburns and risk of cutaneous melanoma: does age matter? A comprehensive meta-analysis. Ann Epidemiol. 2008; 18(8):614-627. [PubMed: 18652979]

36. Gallagher RP, Spinelli JJ, Lee TK. Tanning beds, sunlamps, and risk of cutaneous malignant melanoma. Cancer Epidemiol Biomarkers Prev. 2005; 14(3):562-566. [PubMed: 15767329]

37. The association of use of sunbeds with cutaneous malignant melanoma and other skin cancers: A systematic review. Int J Cancer. 2007; 120(5):1116-1122. [PubMed: 17131335]

38. Cokkinides V, Weinstock M, Lazovich D, Ward E, Thun M. Indoor tanning use among adolescents in the US, 1998 to 2004. Cancer. 2009; 115(1):190-198. [PubMed: 19085965]

39. Hoerster KD, Garrow RL, Mayer JA, Clapp EJ, Weeks JR, Woodruff SI, et al. Density of indoor tanning facilities in 116 large U.S. cities. Am J Prev Med. 2009; 36(3):243-246. [PubMed: 19215849]

40. Meyskens FL Jr. Berwick M. UV or not UV: metals are the answer. Cancer Epidemiol Biomarkers Prev. 2008; 17(2):268-270. [PubMed: 18268109]

41. Wolff T, Tai E, Miller T. Screening for skin cancer: an update of the evidence for the U.S. Preventive Services Task Force. Ann Intern Med. 2009; 150(3):194-198. [PubMed: 19189909]

42. Fears TR, Guerry D, Pfeiffer RM, Sagebiel RW, Elder DE, Halpern A, et al. Identifying individuals at high risk of melanoma: a practical predictor of absolute risk. J Clin Oncol. 2006; 24(22):3590-3596. [PubMed: 16728488]

43. Ford D, Bliss JM, Swerdlow AJ, Armstrong BK, Franceschi S, Green A, et al. Risk of cutaneous melanoma associated with a family history of the disease. The International Melanoma Analysis Group (IMAGE). Int J Cancer. 1995; 62(4):377-381. [PubMed: 7635561]

44. Rutter JL, Bromley CM, Goldstein AM, Elder DE, Holly EA, Guerry D, et al. Heterogeneity of risk for melanoma and pancreatic and digestive malignancies: a melanoma case-control study. Cancer. 2004; 101(12):2809-2816. [PubMed: 15529312]

45. Goldstein AM, Chan M, Harland M, Hayward NK, Demenais F, Bishop DT, et al. Features associated with germline CDKN2A mutations: a GenoMEL study of melanoma-prone families from three continents. J Med Genet. 2007; 44(2):99-106. [PubMed: 16905682]

46. Bishop DT, Demenais F, Goldstein AM, Bergman W, Bishop JN, Bressac-de PB, et al. Geographical variation in the penetrance of CDKN2A mutations for melanoma. J Natl Cancer Inst. 2002; 94(12):894-903. [PubMed: 12072543]

47. Begg CB, Orlow I, Hummer AJ, Armstrong BK, Kricker A, Marrett LD, et al. Lifetime risk of melanoma in CDKN2A mutation carriers in a population-based sample. J Natl Cancer Inst. 2005; 97(20):1507-1515. [PubMed: 16234564]

48. Goldstein AM, Chan M, Harland M, Gillanders EM, Hayward NK, Avril MF, et al. High-risk melanoma susceptibility genes and pancreatic cancer, neural system tumors, and uveal melanoma across GenoMEL. Cancer Res. 2006; 66(20):9818-9828. [PubMed: 17047042]

49. Goldstein AM. Familial melanoma, pancreatic cancer and germline CDKN2A mutations. Hum Mutat. 2004; 23(6):630. [PubMed: 15146471]

50. Gerstenblith MR, Goldstein AM, Fargnoli MC, Peris K, Landi MT. Comprehensive evaluation of allele frequency differences of MC1R variants across populations. Hum Mutat. 2007; 28(5):495505. [PubMed: 17279550]

51. Raimondi S, Sera F, Gandini S, Iodice S, Caini S, Maisonneuve P, et al. MC1R variants, melanoma and red hair color phenotype: a meta-analysis. Int J Cancer. 2008; 122(12):2753-2760. [PubMed: 18366057] 
52. Landi MT, Bauer J, Pfeiffer RM, Elder DE, Hulley B, Minghetti P, et al. MC1R germline variants confer risk for BRAF-mutant melanoma. Science. 2006; 313(5786):521-522. [PubMed: 16809487]

53. Fargnoli MC, Pike K, Pfeiffer RM, Tsang S, Rozenblum E, Munroe DJ, et al. MC1R variants increase risk of melanomas harboring BRAF mutations. J Invest Dermatol. 2008; 128(10):24852490. [PubMed: 18368129]

54. Landi MT, Kanetsky PA, Tsang S, Gold B, Munroe D, Rebbeck T, et al. MC1R, ASIP, and DNA repair in sporadic and familial melanoma in a Mediterranean population. J Natl Cancer Inst. 2005; 97(13):998-1007. [PubMed: 15998953]

55. Goldstein AM, Landi MT, Tsang S, Fraser MC, Munroe DJ, Tucker MA. Association of MC1R variants and risk of melanoma in melanoma-prone families with CDKN2A mutations. Cancer Epidemiol Biomarkers Prev. 2005; 14(9):2208-2212. [PubMed: 16172233]

56. Goldstein AM, Chaudru V, Ghiorzo P, Badenas C, Malvehy J, Pastorino L, et al. Cutaneous phenotype and MC1R variants as modifying factors for the development of melanoma in CDKN2A G101W mutation carriers from 4 countries. Int J Cancer. 2007; 121(4):825-831. [PubMed: 17397031]

57. Zuo L, Weger J, Yang Q, Goldstein AM, Tucker MA, Walker GJ, et al. Germline mutations in the p16INK4a binding domain of CDK4 in familial melanoma. Nat Genet. 1996; 12(1):97-99. [PubMed: 8528263]

58. Brown KM, Macgregor S, Montgomery GW, Craig DW, Zhao ZZ, Iyadurai K, et al. Common sequence variants on 20q11.22 confer melanoma susceptibility. Nat Genet. 2008; 40(7):838-840. [PubMed: 18488026]

59. Sulem P, Gudbjartsson DF, Stacey SN, Helgason A, Rafnar T, Magnusson KP, et al. Genetic determinants of hair, eye and skin pigmentation in Europeans. Nat Genet. 2007; 39(12):14431452. [PubMed: 17952075]

60. Sulem P, Gudbjartsson DF, Stacey SN, Helgason A, Rafnar T, Jakobsdottir M, et al. Two newly identified genetic determinants of pigmentation in Europeans. Nat Genet. 2008; 40(7):835-837. [PubMed: 18488028]

61. Gudbjartsson DF, Sulem P, Stacey SN, Goldstein AM, Rafnar T, Sigurgeirsson B, et al. ASIP and TYR pigmentation variants associate with cutaneous melanoma and basal cell carcinoma. Nat Genet. 2008; 40(7):886-891. [PubMed: 18488027] 


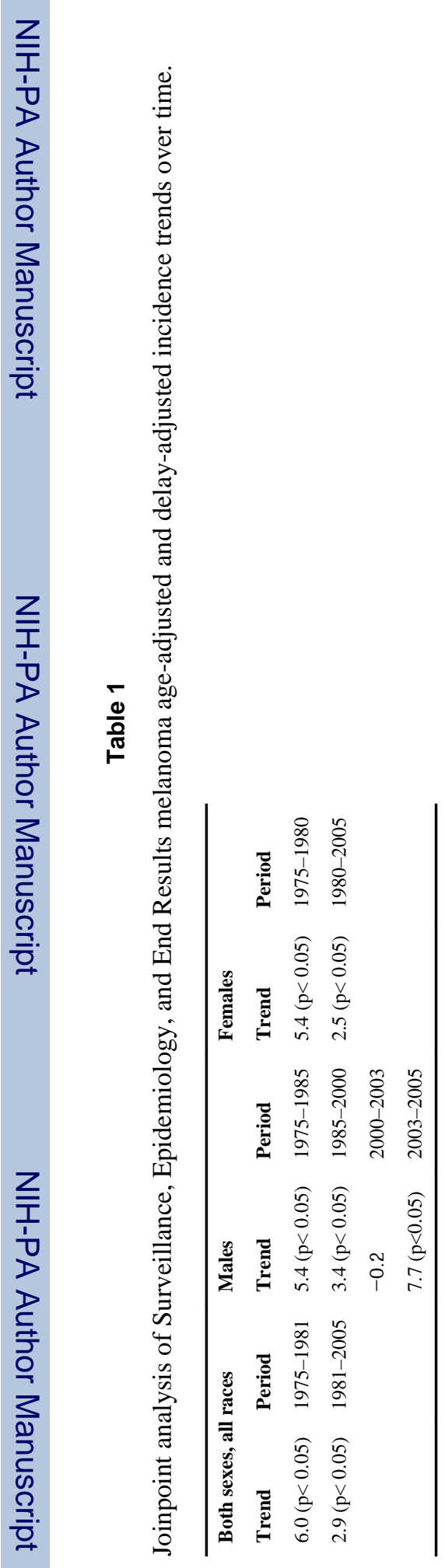

Hematol Oncol Clin North Am. Author manuscript; available in PMC 2011 December 8. 
Table 2

Summary risks for melanoma by identified risk factors

\begin{tabular}{|c|c|c|}
\hline \multicolumn{3}{|l|}{ Risk Factor } \\
\hline CDKN2A mutation, high risk family & Penetrance at 80 & $0.67(0.31-0.96)^{46}$ \\
\hline Europe & & 0.58 \\
\hline U.S. & & 0.76 \\
\hline Australia & & 0.91 \\
\hline$C D K N 2 A$ mutation, unselected & Penetrance at 80 & $0.28(0.18-0.40)^{47}$ \\
\hline$M C 1 R$ RHC & $\mathrm{RR}$ & $1.4-2.4^{51}$ \\
\hline rhe & $\mathrm{RR}$ & 1.15 (NS)-2.5 \\
\hline \multicolumn{3}{|l|}{ Nevi (total body) } \\
\hline $16-40$ & $\mathrm{RR}$ & $1.47(1.36-1.59)^{15}$ \\
\hline $101-120$ & $\mathrm{RR}$ & $6.89(4.63-10.25)$ \\
\hline Dysplastic nevi (dichotomous) & $\mathrm{RR}$ & $10(5.0-20)^{15}$ \\
\hline $1 \mathrm{DN}$ & $\mathrm{RR}$ & $1.6(1.38-1.85)$ \\
\hline $5+\mathrm{DN}$ & $\mathrm{RR}$ & $10(5.1-22)$ \\
\hline Light skin color & $\mathrm{RR}$ & $2.06(1.68-2.52)^{29}$ \\
\hline Poor tanning ability & $\mathrm{RR}$ & $2.09(1.67-2.58)$ \\
\hline Light eye color & $\mathrm{RR}$ & $1.47(1.28-1.69)$ \\
\hline Light hair color & $\mathrm{RR}$ & $1.78(1.63-1.95)$ \\
\hline Freckling & $\mathrm{RR}$ & $2.1(1.8-2.5)$ \\
\hline Total sun exposure & $\mathrm{RR}$ & $1.34(1.01-1.77)^{33}$ \\
\hline \multirow[t]{2}{*}{ Sunburns } & $\mathrm{RR}$ & 2.03 (1.73-2.37) Sunbed use \\
\hline & $\mathrm{RR}$ & $1.25(1.05-1.49)^{36}$ \\
\hline
\end{tabular}

